\title{
Water Distribution in Laterals and Units of Subsurface Drip Irrigation. II: Field Evaluation
}

\author{
Leonor Rodríguez-Sinobas ; María Gil ; Luis Juana, M.ASCE ; and Raúl Sánchez
}

\begin{abstract}
The performance of drip irrigation and subsurface drip irrigation (SDI) laterals has been compared. Two emitter models (one compensating and the other noncompensating) were assessed. Field tests were carried out with a pair of laterals working at the same inlet pressure. A procedure was developed that recorded head pressures at both lateral extremes and inlet flow during irrigation. Both models showed similar behavior and soil properties affected their discharge. On the other hand, the performance of a field SDI unit of compensating emitters was characterized by measuring pressures at different points and inlet flow. Finally, the distribution of water and soil pressure in the laterals and the unit were predicted and irrigation uniformity and soil pressure variability were also determined. Predictions agreed reasonably well with the experimental observations. Thus, the methodology proposed could be used to support the decision making for the design and management of SDI systems.
\end{abstract}

CE Database subject headlngs: Trickle irrigation; Water distribution systems; Hydraulics; Subsurface environment.

\section{Introduction}

Subsurface drip inigation SDI is one of the most advanced inigation technology. The frequent application of small amounts of water to the soil through buried emitters allow for high crop production without leaching or runoft. Only the amount of water required by the crop on a daily, or other basis, need be diverted from the system (Ayars et al. 1999). Phene et al. (1992) observed that in most soils, water remains in the root zone for utilization by growing plants, only a small amount went to deep percolation. In addition, they found that some accumulation of nitrate-nitrogen occurred at the soil surface in tomatoes and cantaloupes after 3 years of cultivation. Also, a small amount leached below the root zone. Consequently, groundwater contamination and runoff from nonpoint sources containing agricultural contaminants is reduced if not eliminated entirely thus helping to protect water quality.

Drawbacks associated with the practice of SDI are reductions in emitter discharge and possible surfacing of water resulting from positive pressure develop at the emitter outlet. Shani et al. (1996) measured the overpressure $h_{s}$ at the discharge point of single emitters under field conditions. $h_{s}$ increased rapidly at the beginning of inigation until it approaches a final value after 10 to $15 \mathrm{~min}$. Values of $h_{s}$ up to $8 \mathrm{~m}$ were recorded on different emitter types with various discharges. The pressure build up $h_{s}$ in the soil reduces the pressure difference across the emitter and, subsequently, the emitter discharge decreases from 10 up to $50 \%$. The writers recommended the selection of compensating emitters in soils having low saturated hydraulic conductivity since minimal change in their discharge was observed.

Lazarovitch et al. (2005) measured $h_{s}$, also under field conditions, in two emitters introduced in a perforate plastic sphere, although the maximum $h_{s}$ values observed, up to $3 \mathrm{~m}$, were lower than the observations of Shani et al. (1996) for the same emitter flow rate and similar soils. Gil Rodríguez et al. (2007) also examined the influence of soil properties in laboratory tests on pots containing uniform soil with the same bulk density. However, $h_{s}$ values measured for the same flow rate and similar soils were lower than those obtained in the field by the other writers. Under field conditions, the soil structure decreases soil water infiltration determining an increment of water pressure around the emitter.

In their experiments on pots, Gil et al. (2008) reported that the coefficient of variation of emitter flow $\mathrm{CV}_{q}$ in the pressurecompensating models was similar on surface and buried emitters. Thus, the irrigation uniformity would be similar in both cases, under the hypotheses that internal minus extemal pressure head is minor than or equal to the lower limit of emitter compensation range.

Phene et al. (1992) determined the water application uniformity of SDI laterals from the flow collected in excavated emitters. They compared the measured coefficient of uniformity with the corresponding value calculated by a computer program based on the energy gradient line, the revised energy gradient line and the step by step methods. Although all the methods provided good agreement with experimental determinations, the first two showed better accuracy.

Sadler et al. (1995) observed a maximum increase in emitter flow rate, between 2.8 and $4.0 \%$, in $12-\mathrm{m}$ long laterals when emitters are excavated. They postulated that the effect of excavat- 
ing emitters would not cause significant errors in the determination of water application uniformity. Safi et al. (2008) observed a rise of about $7 \%$ in flow rate when the emitters were excavated. They also observed that the irrigation uniformity of excavated drip tapes, after 3 years in the field, was lower than the uniformity of new tapes deployed over the soil. Ayars et al. (2001) determined uniformities from 75 to $90 \%$ in field evaluations of several SDI laterals.

Recent experimental works have shown an interest on the management of SDI on crop production (Camp et al. 1997; Ayars et al. 1999; Bordovsky and Porter 2006; Grabow et al. 2006). However, few papers have presented experimental data on measuring water application uniformity in field laterals, and no evaluation method has been yet reported to measure, in situ, the flow of buried emitters.

On the other hand, earlier research has involved in studying the effect of soil properties on the discharge of a single SDI emitter, and on simulating lateral flow-rate distribution considering soil variability. Nevertheless, neither field studies in laterals nor in units have been yet assessed to confirm the simulations. The first goal of this article is to assess and compare, under controlled inlet head pressures, the behavior of laterals in SDI and surface drip irrigation. A field procedure will be proposed for that purpose. In addition, a complete evaluation of a field SDI unit will be also achieved. The second goal is to check the methodology detailed in the companion paper to predict water distribution in the laterals and the unit evaluated in the field. Thus, the computer program, that calculates the looped network, and the geostatistical modeling software, that estimates soil variability, will be coupled for prediction of water distribution throughout the unit and along the laterals. Accordingly, soil pressure at the emitter outlet, irrigation uniformity and soil pressure variability would be also estimated.

\section{Material and Methods}

\section{Field Experiments with SDI Laterals}

Experimental evaluation of the lateral performance under SDI was conducted on a zero slope loam soil at the research facility located at the "Centro Nacional de Tecnología de Regadíos" in San Fernando de Henares, Spain. The experimental site was slip plowed to $50 \mathrm{~cm}$ to thoroughly mix the profile and eliminate any compacted layers, then chiseled to $40 \mathrm{~cm}$, disked, and harrowed. A $50-\mathrm{m}$ long laterals of integrated emitters were deployed, approximately, $30 \mathrm{~cm}$ below the surface. One regular emitter (A) and other pressure-compensating (B) emitter were evaluated. Emitters spacing was $30 \mathrm{~cm}$. Fig. 1(a) shows the experimental set up including 14 laterals (seven of each emitter model) connected to the submain. Water was supplied by three pressurized valves and it was filtered prior to the diversion to the laterals. Irrigation was applied for $30 \mathrm{~min}$ maintaining a constant lateral inlet pressure by a pressure regulator.

Soil water content at different depths was determined by the gravimetric method. Soil samples were collected at the three first emitters that worked at a head pressure of $10 \mathrm{~m}$, located at the extreme laterals at the end of irrigation. Similarly at the beginning of irrigation, soil samples at three other points, adjacent to the extreme laterals, were also collected. Then, soil samples were dried oven at $105^{\circ} \mathrm{C}$ during $48 \mathrm{~h}$.

In each test, water was simultaneously supplied to a pair of laterals working at a similar inlet head pressure. Three irrigation

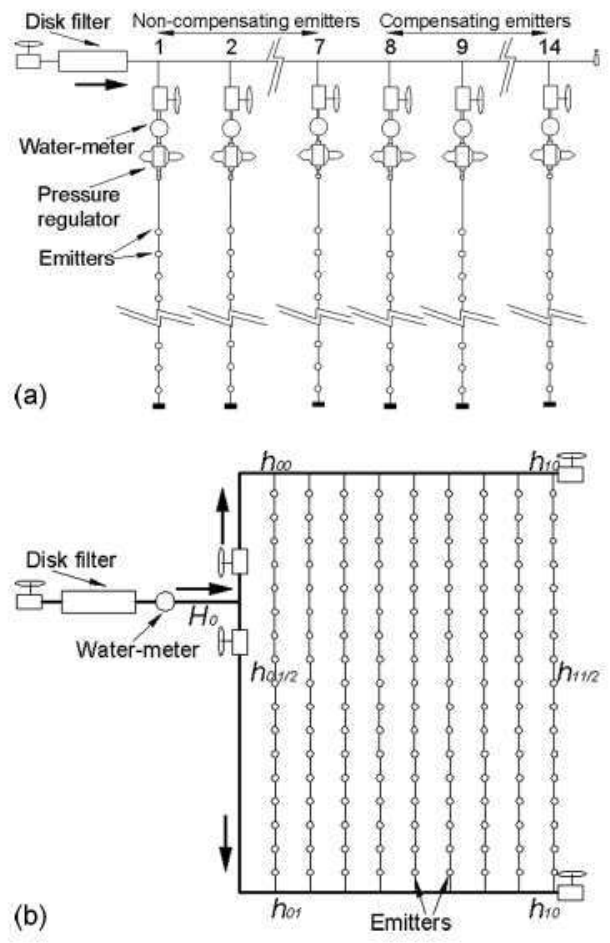

Fig. 1. Layout of the experimental setup for SDI field evaluation: (a) laterals; (b) unit

tests were programmed for the laterals of each emitter type with inlet head pressures $h_{0}=8,10$, and $15 \mathrm{~m}$ in the first, second, and third lateral pairs, respectively. Pressures at the upstream and downstream end of the lateral were recorded every $10 \mathrm{~s}$ by pressure transducers accurate to $\pm 0.01 \mathrm{~m}$. Inlet lateral flow rates were also calculated by recording the time corresponding to a fixed volume ( 3 or $5 \mathrm{~L}$ ) that was measured in a Woltman water meter with a minimum reading unit of $0.1 \mathrm{~L}$. In addition, 12 surface laterals similar to those evaluated in the field were tested in the laboratory under similar inlet pressures and same experimental procedure than in the SDI laterals. Also, these tests were used to determine local head losses at the emitter insertion $l_{e}$ (see Table 1). Likewise, other hydraulic characteristics of emitters such as: their flow rate-pressure head relationship and their manufacture CVs were obtained on an emitter testing bench on samples of 24 units of each emitter model that were randomly selected from a population over 300 (see Table 1).

\section{Field Evaluation of SDI Units}

The sketch of Fig. 1(b) shows the SDI unit of compensating emitters that was evaluated twice in different days. This unit has been in the field since the year 2000. The emitters are spaced $0.6 \mathrm{~m}$ and have a nominal discharge of $3.5 \mathrm{~L} / \mathrm{h}$ with compensation range between 8 to $40 \mathrm{~m}$. They are buried at $30-\mathrm{cm}$ depth in a loamy

Table 1. Hydraulic Characterization of Tested Laterals

\begin{tabular}{cccccc}
\hline & $\begin{array}{c}k \\
(\mathrm{~L} / \mathrm{h}) / \mathrm{mca}^{x}\end{array}$ & $x$ & $\mathrm{CV}_{m}$ & $\begin{array}{c}q_{n} \\
(\mathrm{~L} / \mathrm{h})\end{array}$ & $\begin{array}{c}l_{e} \\
(\mathrm{~m})\end{array}$ \\
\hline $\mathrm{A}$ & 1.20 & 0.48 & 0.058 & 3.7 & 0.76 \\
$\mathrm{~B}$ & 3.40 & 0.02 & 0.032 & 3.6 & 0.76 \\
\hline
\end{tabular}

Note: $q_{n}=$ emitter nominal discharge and $l_{e}=$ equivalent length at the emitter insertion. 
Table 2. Mean Values of Variables Measured during Irigation of Subsurface Laterals

\begin{tabular}{|c|c|c|c|c|c|c|c|c|c|c|c|c|}
\hline & \multicolumn{6}{|c|}{ Compensating emitter } & \multicolumn{6}{|c|}{ Noncompensating emitter } \\
\hline & $1 \mathrm{~A}$ & $2 \mathrm{~A}$ & $3 \mathrm{~A}$ & $4 \mathrm{~A}$ & $5 \mathrm{~A}$ & $6 \mathrm{~A}$ & 1B & 2B & $3 \mathrm{~B}$ & $4 \mathrm{~B}$ & $5 \mathrm{~B}$ & $6 \mathrm{~B}$ \\
\hline $\bar{Q}(\mathrm{~L} / \mathrm{h})$ & 459.4 & 480.7 & 545.8 & 548.0 & 659.3 & 645.6 & 569.1 & 602.7 & 645.2 & 668.4 & 637.4 & 653.4 \\
\hline $\bar{q}(\mathrm{~L} / \mathrm{h})$ & 2.76 & 2.88 & 3.27 & 3.29 & 3.96 & 3.87 & 3.41 & 3.62 & 3.87 & 4.01 & 3.82 & 3.92 \\
\hline $\bar{h}_{0}(\mathrm{~m})$ & 8.0 & 8.6 & 11.4 & 11.1 & 16.1 & 15.6 & 8.3 & 8.0 & 11.5 & 11.6 & 15.5 & 164 \\
\hline $\bar{h}_{L}(\mathrm{~m})$ & 5.1 & 5.9 & 7.6 & 7.7 & 11.1 & 10.9 & 3.3 & 2.7 & 5.6 & 5.6 & 9.3 & 10.0 \\
\hline $\bar{h} f(\mathrm{~m})$ & 2.8 & 2.8 & 3.7 & 3.4 & 5.0 & 4.7 & 5.0 & 5.3 & 6.0 & 6.1 & 6.2 & 6.4 \\
\hline
\end{tabular}

soil. As seen in this figure, water can come into the unit by two valves: one located upstream of the unit and the other located downstream of it. The evaluations considered different scenarios for water application into the unit: the two valves are fully open (2V): the upstream valve is fully open while the other valve is close (UP); and the downstream valve is fully open while the other valve is close (DW). In each evaluation, pressures at the inlet, the downstream end and at an intermediate point of the first and last laterals were measured at time intervals with digital manometers, accurate to $\pm 0.01 \mathrm{~m}$. The manometers were previously calibrated in the laboratory. The inlet flow unit at the beginning and the end of irrigation were also calculated with the readings monitored in a Woltman water meter. Complementarily, a sample of 16 pairs of emitters was selected following the procedure for field evaluation of surface drip inigation units proposed by Juana et al. (2007). First, the emitters were excavated and their flows collected in a plastic container during $5 \mathrm{~min}$. Then, the volume of each container was measured with a graduated cylinder ( $1 \mathrm{~L}$ ) with divisions every $10 \mathrm{~mL}$

Finally, the elevations at 22 points throughout the SDI unit were determined using a theodolite; 16 points corresponded to the location of the emitters pair sample; four to the SDI comers and the last two to the locations at the half length of the extreme laterals. The height at the remaining unit's emitters was determined by linear interpolation

On the other hand, the discharge of the emitter's sample was analyzed with a factorial design ANOVA. This type of analysis shows the contribution of each factor in relation to the total observed variance in emitter flow. Three factors were considered: hydraulic variation due to the lateral location in the submain $i$ : hydraulic variation due to the emitter location in the lateral $j$; and emitter's manufacture and ware variation $m$ (Juana et al. 2007). Such contribution is expressed as CV which is commonly used in irrigation practice.

The performance of laterals and SDI unit were simulated with the methodology presented in the companion paper. Soil properties corresponded to the loamy soil (mean saturated hydraulic conductivity $K_{s}=2.89 \times 10^{-6} \mathrm{~m} / \mathrm{s}$ and mean soil factor $\alpha$ $=12.9 \mathrm{~m}^{-1}$ ) as indicated by Carsel and Parrish (1988) (see Table 1 in the companion paper). Spatial variability of soil properties has been simulated considering the $\mathrm{CV}$ of $K_{s}$ and $\alpha, \mathrm{CV}=0.5$; and its coefficient of correlation $\rho=0.7$. For the cavity radius $r_{0}$ the uniform distribution is assumed with bounds of $10 \%$.

\section{Results and Discussion}

\section{Assessment of SDI Laterals in the Fleld}

The hydraulic characteristics of the evaluated emitters are described in Table 1. Likewise, Table 2 reports the measured mean values of: inlet flow $\bar{Q}$, inlet head $\bar{h}_{0}$, downstream head pressure $\bar{h}_{L}$, head losses $\bar{h} f$, and emitter discharge $\bar{q}$.

Gravimetric water content at $30-\mathrm{cm}$ depth before irrigation was $14 \%$. It increased to 16 and $21 \%$ in compensating Emitter B and in regular Emitter A, respectively, after inigation. Emitter B had less water content since its discharge was smaller than Emitter A.

The Figs. 2 and 3 show the variation of lateral inflow $Q$ and lateral head losses $h f$, respectively, during irrigation. Each pair of laterals behaved similarly. As was observed in single emitters (Shani et al. 1996: Gil et al. 2008), $Q$ decreased rapidly for 600 $800 \mathrm{~s}$ and then approached a final value as the time advanced. Consequently, $h f$ reduced and the head pressure at the lateral downstream $h_{L}$ increased. Reduction of head losses in Emitter B was more pronounced than in emitter A within $600-800 \mathrm{~s}$, particularly, at the higher inlet pressures. On the contrary, this tendency was not evidenced in the surface laterals with the exception of Emitter B that showed a slight decrease in its head losses within $300 \mathrm{~s}$ at the highest $h_{0}$.

The above results point out that overpressure $h_{s}$ at the emitter outlet increases at the start of the irrigation until stabilizes thus, confirming the trend observed in single emitters (Shani et al. 1996; Lazarovitch 2005; Gil Rodríguez et al. 2007). Moreover, these results evidence the effect of the soil properties in the discharge of both emitters, specifically Emitter B. The elastomer of this emitter would not have reached its full compensating condition at the end of irrigation $(30 \mathrm{~min})$. To verify this hypothesis, a sample of new 24 Emitters B were sorted and tested under similar pressures than the field in an emitter testing bench for, at least, 2 h. Results are depicted in Fig. 4 .

Discharge diminishes rapidly at the beginning of operation; a 2.5 and $3 \%$ discharge reduction is observed after $30 \mathrm{~min}$ for $h_{0}$ $=10.2$ and $14.8 \mathrm{~m}$, respectively (see Fig. 4). It stabilizes sooner at the highest pressure. Therefore, it could be expected that the discharge variation of Emitter $B$ in the field would be similar to the testing bench for the same time, although the lateral pressure variation has not been considered. As awaited, since the lowest pressure $(8 \mathrm{~m})$ corresponds to the lower limit of the emitter compensation range, the emitter behaved as a regular emitter rather than pressure compensating.

Rodriguez-Sinobas et al. (1999) reported a similar behavior in one model of compensating emitter: the discharge decreased over the operating time until stabilizes. This effect was ascribed to the fatigue of elastomer. The elastomer material may suffer fatigue when being held under pressure and its structural characteristics may change. When irrigation is finished pressure is cancelled and the elastomer relaxes and surmounts the deformation caused by pressure. The longer the time elapsed between successive irrigations the longer the time for the elastomer to return to its initial 


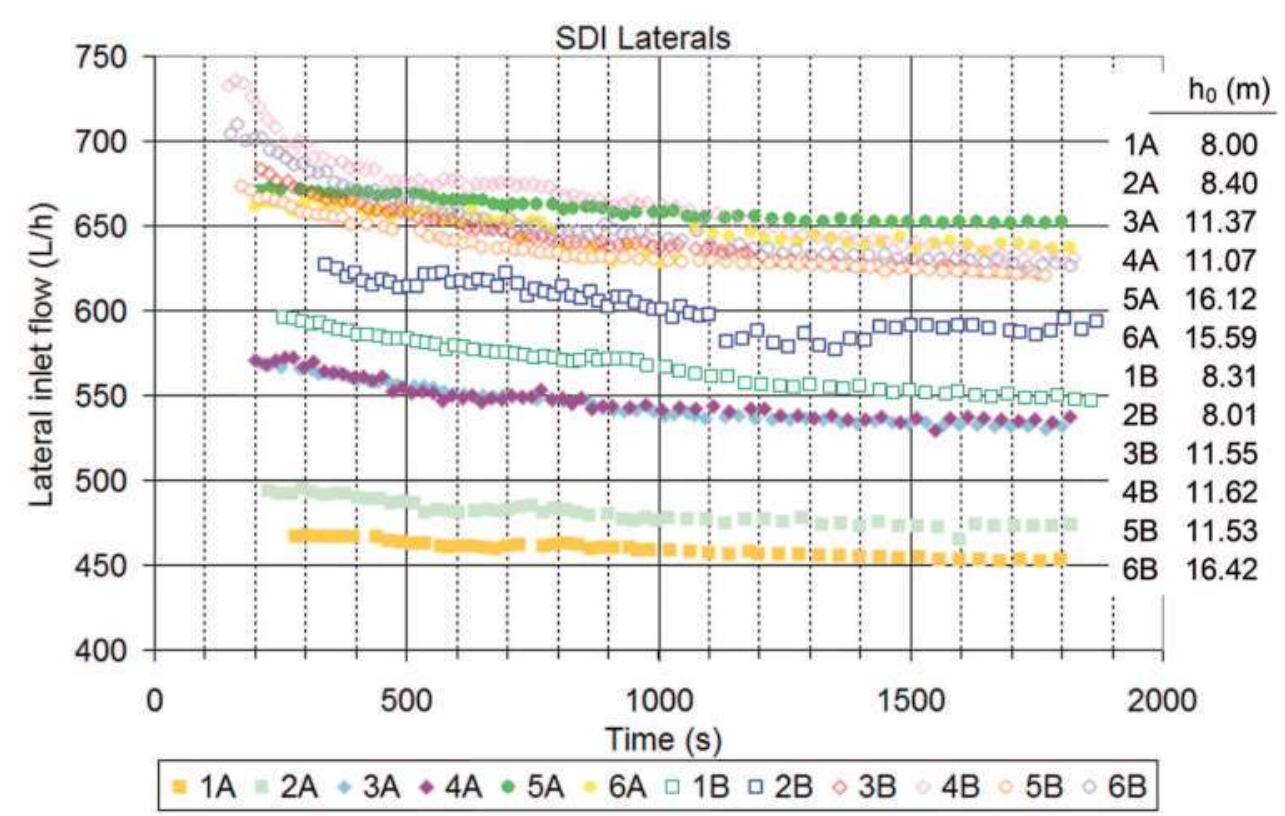

(a)

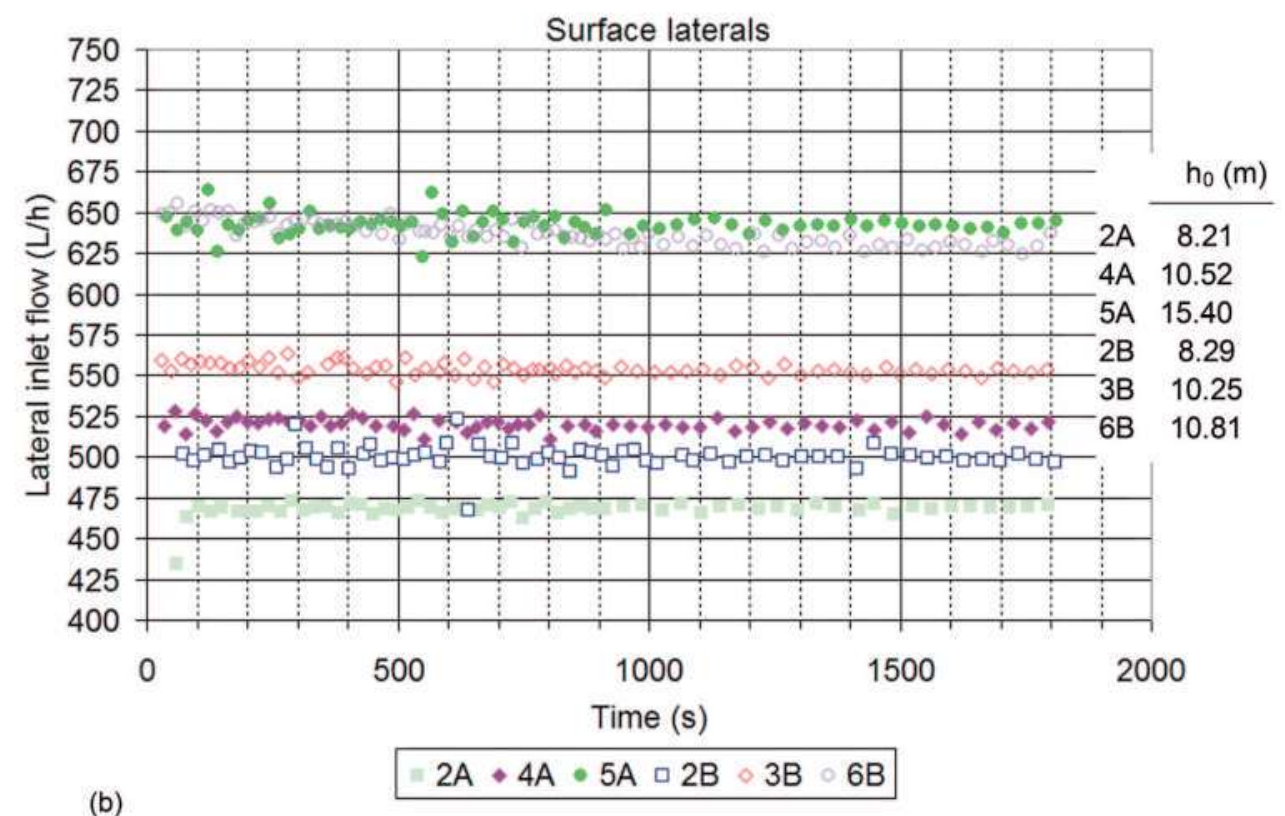

Fig. 2. (Color) Variation of lateral inlet flow during irrigation: (a) surface laterals; (b) subsurface laterals

condition. This behavior will be conditioned by elastomer material and its relative size. From the two compensating emitters evaluated, the one with elastomer area of $2.56 \times 10^{-4} \mathrm{~m}^{2}$, exhibited the effect while the other, with elastomer area of 0.096 $\times 10^{-4} \mathrm{~m}^{2}$, performed normally. Comparatively, the elastomer area of Emitter B is $0.78 \times 10^{-4} \mathrm{~m}^{2}$.

Discharge variation of lateral inflow within the operation time is displayed in Fig. 5. The performance of the surface laterals with Emitter B was similar to the observed in the emitter sample. Their maximum discharge variation was $3.5,2$, and less than $1 \%$ for $h_{0}=15,10$, and $8 \mathrm{~m}$, respectively. The lowest pressure, exhibits a trend with alternation of positive (discharge increases) and negative values (discharge decreases) that coincides with the performance of Emitter A. Surface and buried laterals of Emitter B would work as a regular emitter since its lowest range for pres- sure compensation is $8 \mathrm{~m}$. Likewise, lateral discharge variation for SDI laterals was three times larger than the surface laterals for similar inlet pressure in both emitters. It is worth to note that the smallest and the largest pressures in Emitter A show comparable variation.

The performance of laterals commented above agrees with other tests carried out with the same laterals and the same inlet pressures a week before the ones reported here. The purpose of these tests was to check out the operation of the irrigation system and the equipment. The gravimetric soil water content was $12 \%$ at the beginning of irrigation. Finally, results illustrate the effect of soil properties in both emitters contradicting the observations made in single compensating emitters in which the soil did not affect (Shani et al. 1996; Gil Rodríguez et al. 2007). 


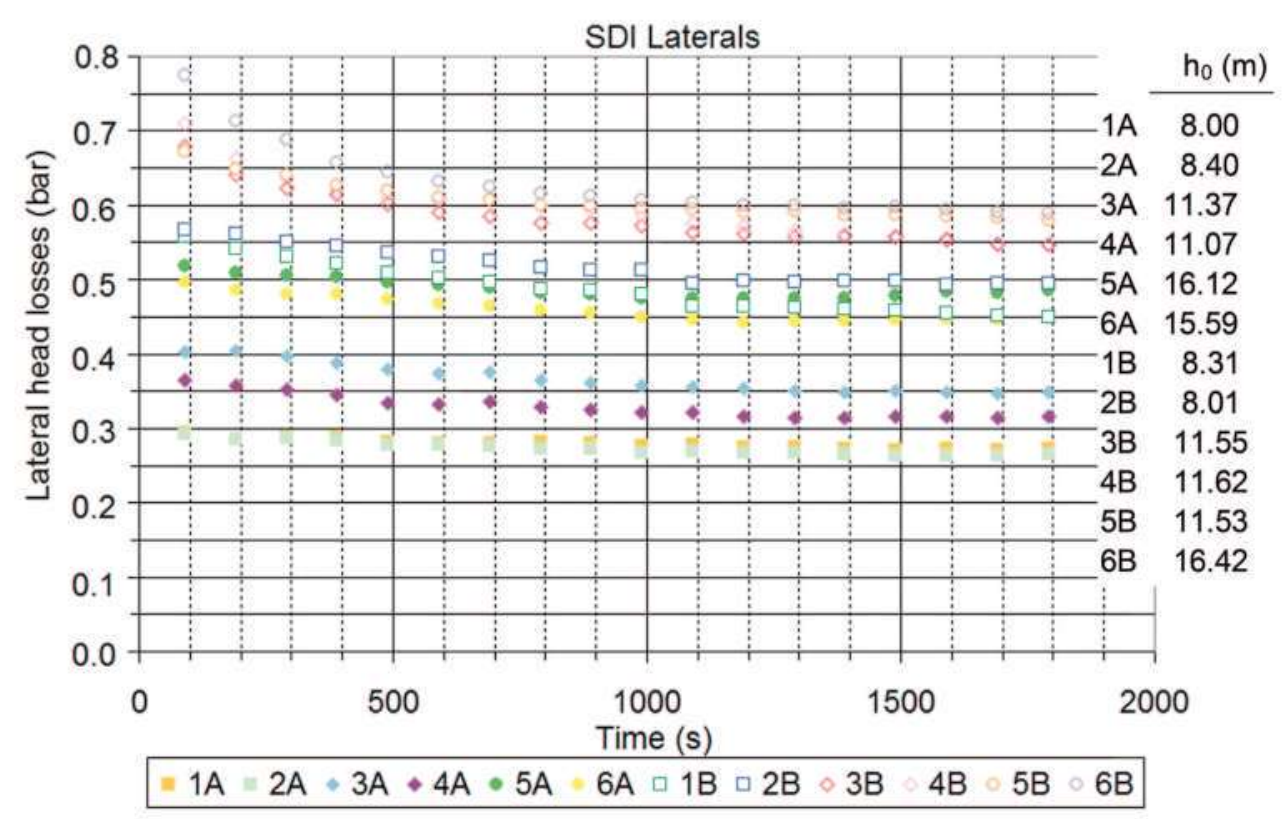

(a)

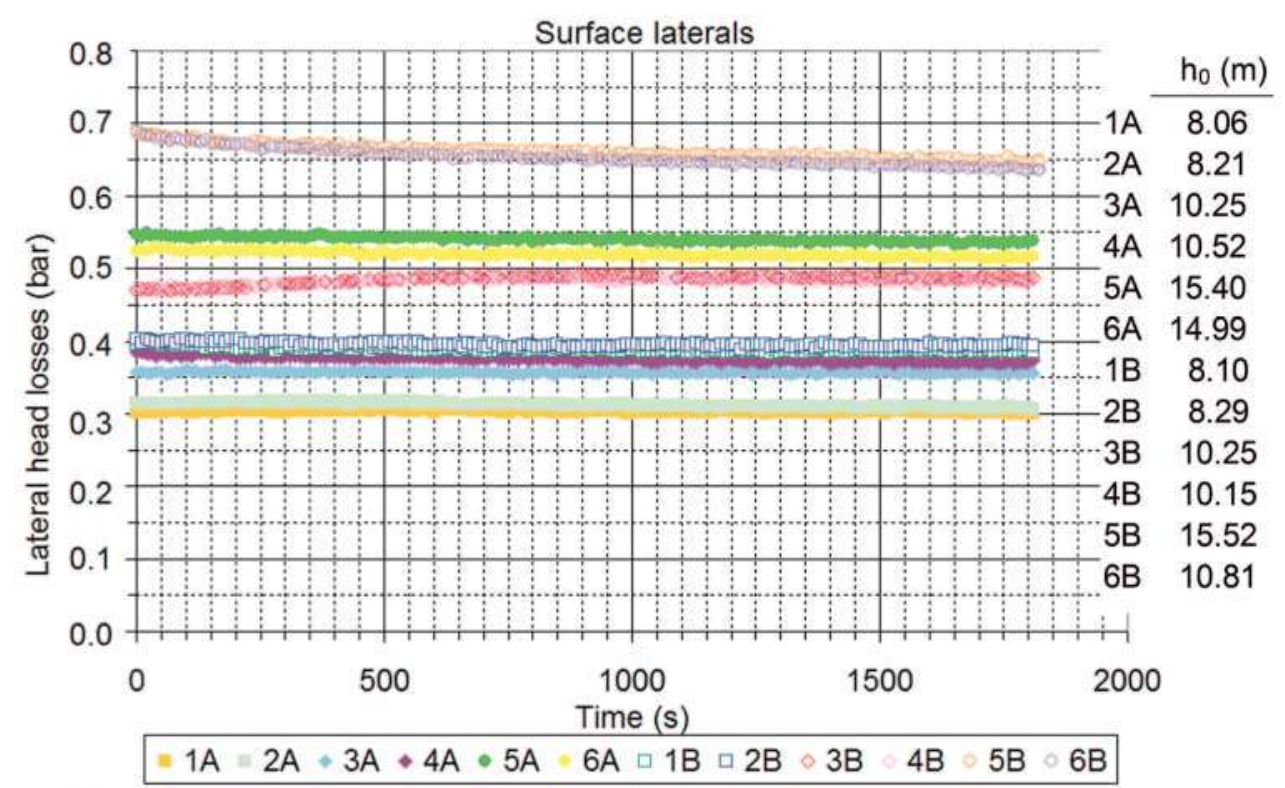

(b)

Fig. 3. (Color) Variation of lateral head losses during: (a) surface laterals; (b) subsurface laterals

\section{Characterization and Evaluation of SDI Units}

The topography of the SDI unit is described in Fig. 6. As observed, the soil slope is not uniform; the lowest point corresponds to the downstream end of the first lateral $h_{01}$. After $45 \mathrm{~min}$ of irrigation, flooding came out in some zones of the soil surface. These were mostly located at the lowest points although some of them were also observed at higher heights.

\section{Uniformity of Water Distribution}

Table 3 displays emitter's discharges determined in the two evaluations. As seen, the discharge of each emitter is variable; it has a CV with a maximum value of 0.42 , a minimum value of 0.01 and a mean value of 0.15 . The mean of emitter discharge is $3.34 \mathrm{~L} / \mathrm{h}$ with a minimum value of $1.87 \mathrm{~L} / \mathrm{h}$ and a maximum value of 4.03 $\mathrm{L} / \mathrm{h}$. No trend is observed in any of the emitters' discharges. Since the emitters are pressure compensating, the above observations

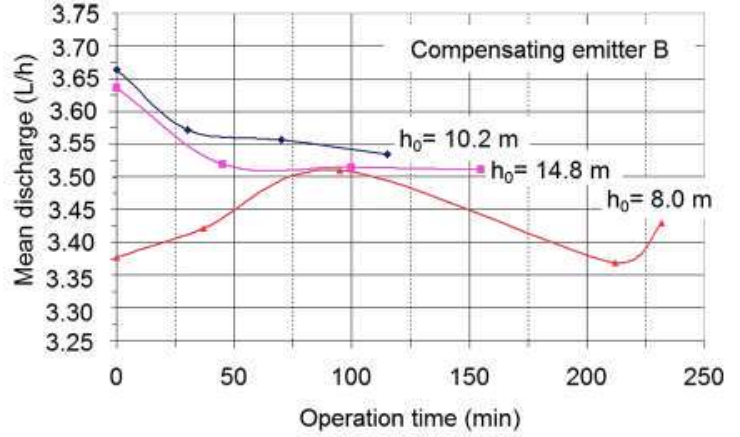

Fig. 4. Variation of mean discharge $q$ with the operation time in a sample of 24 units of compensating Emitters B 

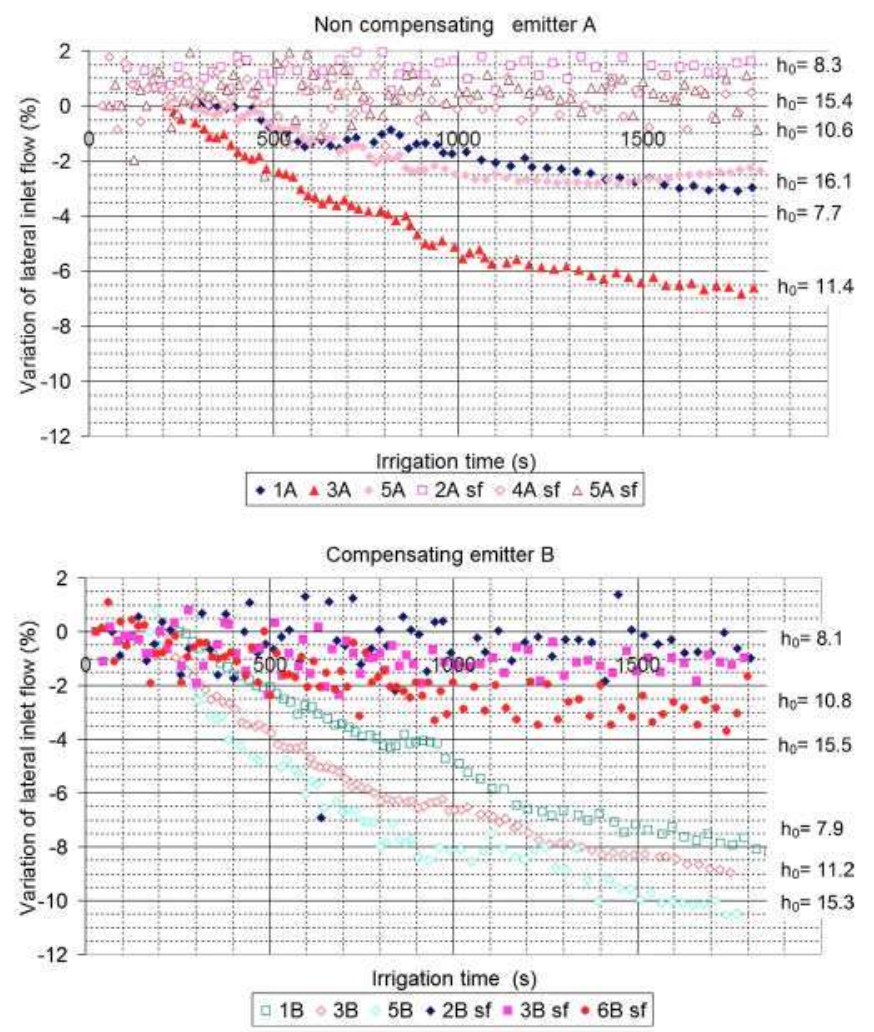

Fig. 5. Variation of inlet flow during: (a) surface laterals; (b) subsurface laterals

(large flow variability and no trend) could be explained by possible deposition of suspended particles during irrigation and root intrusion. Automatic self-cleaning of disk filters was switched off during irrigation.

Table 4 shows the mean value and its variation in each pair of evaluated emitters. Considering that emitters with $\mathrm{CV}>0.1$ are affected by a certain degree of clogging, then, the proportion of emitter clogging was 25 and $37.5 \%$ in the first and the second evaluations, respectively.

Irrigation uniformity in all the evaluations has been expressed by the coefficient of variation of flow $\mathrm{CV}_{q}$ and Christiansen's coefficient $\mathrm{Cu}$. As observed in the tests with both valves fully open (see Table 5), the sample mean flow is between 9 to $15 \%$ higher than in the ones with one fully open valve. Similarly, it has been between 7 to $12 \%$ higher than the one calculated with the flow meter. Although the evaluation experimental error is not known, these observations point out the reduction of emitter discharge due to the soil effect, as it has previously detected in the lateral tests. Furthermore, the unit mean flow would be less than the sample mean flow if the percentage of emitters clogging would have been also taken into consideration.

Irrigation uniformity is higher $(\mathrm{Cu}=91$ and 92) in the evaluation with both valves fully open (2V) (see Table 5), than in the other evaluations $(\mathrm{Cu}=82,85$, and 88$)$. Among the tests with one valve fully open, the lower limit of the emitter's pressure range ( 8 $\mathrm{m}$ ) could be reached in some points of the unit. Therefore, in these points the emitter no longer would behave as a compensating emitter. Likewise, the pressure variation in $2 \mathrm{~V}$ evaluations is less than in evaluations with one valve fully open. Thus, if the emitter would behave as a regular emitter, the uniformity would be higher in $2 \mathrm{~V}$ evaluations as the results highlight.

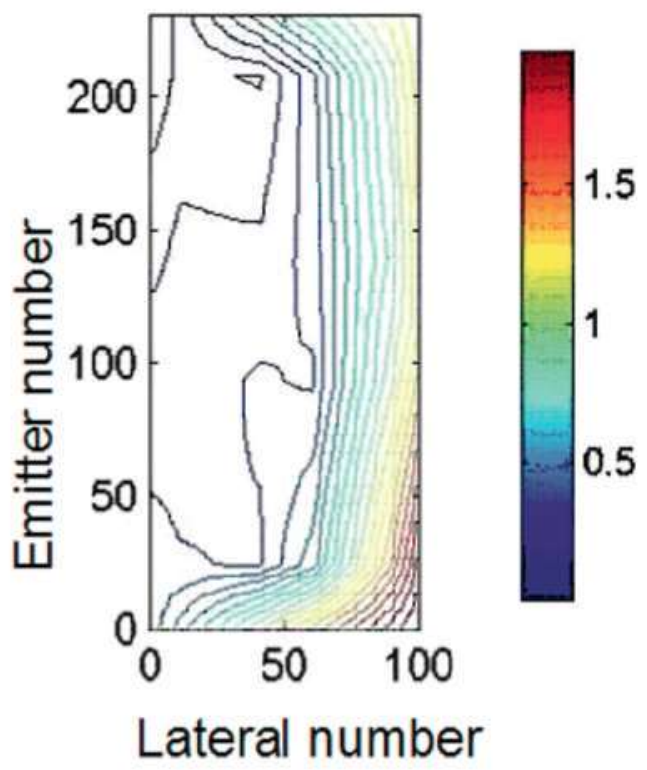

Fig. 6. (Color) Soil elevation in the SDI unit

\section{Hydraulic Characterization}

In evaluations with two valves fully open, submain pressure variation was similar and its head losses were small (less than 2.5 $\mathrm{m})$. These values agree with the ones that would correspond to a submain with the same diameter and under the same evaluations conditions. Sometimes the head losses are negative which could be a consequence of the manometers' accuracy. Pressure variation and head losses in the extreme laterals are also small (less than 1 $\mathrm{m})$; accordingly, pressures along the laterals are alike. In evaluations with only one valve fully open, submain pressure variation and its head losses have been also small (less than $1.3 \mathrm{~m}$ ). However, pressure variation in the extreme laterals is higher than 10 $\mathrm{m}$. For the case with the downstream valve fully open (DW), it has been similar in both laterals but in the upstream valve fully open (UP), the first lateral showed the highest variation. Head losses in both laterals were also similar; they varied from 11 to 14 $\mathrm{m}$.

The CVs of hydraulic variability and emitters' manufacture and wear variability from the factorial design ANOVA are exhibit in Table 6. The coefficient of flow variation $\mathrm{CV}_{q}$ is slightly smaller than the determined in the evaluations (see Table 5). It could be explained because other factor that has not been contemplated in the study might affect emitter discharge variability. The hydraulic variability $\mathrm{CV}_{h}$ was the major factor affecting emitter discharge but the effect of the emitter's manufacturing and wear variation was smaller. If the emitter would have behaved as a pressure compensating, $\mathrm{CV}_{h}$ would have not been the main cause of flow variation. On the other hand, these results also point out a possible effect of soil properties on emitter discharge. The value of $\mathrm{CV}_{m}$ is similar in all evaluations, however the value of $\mathrm{CV}_{h}$ was greater in evaluations for the second day. It should be noted that the percentage of emitter clogging was different each day.

In summary, the emitter is not acting as a compensating, thus the uniformity of water application improved when reducing pressure variability by diverting water through the two inlet valves. The emitter performance could be affected by: clogging, entrapped air, and soil properties; although the effect of each of them cannot be addressed within the conditions of the evalua- 


\begin{tabular}{|c|c|c|c|c|c|c|c|c|c|}
\hline & \multicolumn{5}{|c|}{ Day 1} & \multicolumn{4}{|c|}{ Day 2} \\
\hline & $2 \mathrm{~V}$ & UP & DW & $\begin{array}{c}\bar{q} \\
(\mathrm{~L} / \mathrm{h})\end{array}$ & $\mathrm{CV}$ & $2 \mathrm{~V}$ & UP & $\begin{array}{c}\bar{q} \\
(\mathrm{~L} / \mathrm{h})\end{array}$ & $\mathrm{CV}$ \\
\hline$q_{111}$ & 3.87 & 4.26 & 2.90 & 3.68 & 0.19 & 3.62 & 3.67 & 3.65 & 0.01 \\
\hline$q_{112}$ & 3.93 & 4.22 & 2.95 & 3.70 & 0.18 & 3.36 & 3.54 & 3.45 & 0.04 \\
\hline$q_{121}$ & 3.22 & 2.80 & 2.50 & 2.84 & 0.13 & 3.72 & 3.90 & 3.81 & 0.03 \\
\hline$q_{122}$ & 3.97 & 3.90 & 4.00 & 3.96 & 0.01 & 3.24 & 3.00 & 3.12 & 0.05 \\
\hline$q_{131}$ & 4.07 & 3.17 & 3.19 & 3.48 & 0.15 & 3.55 & 2.90 & 3.23 & 0.14 \\
\hline$q_{132}$ & 4.29 & 3.46 & 3.40 & 3.72 & 0.13 & 3.29 & 2.92 & 3.11 & 0.09 \\
\hline$q_{141}$ & 3.76 & 2.91 & 3.75 & 3.47 & 0.14 & 3.49 & 2.72 & 3.11 & 0.17 \\
\hline$q_{142}$ & 3.49 & 2.82 & 3.65 & 3.32 & 0.13 & 3.58 & 2.90 & 3.24 & 0.15 \\
\hline$q_{211}$ & 3.93 & 4.32 & 2.32 & 3.52 & 0.30 & 3.48 & 3.29 & 3.38 & 0.04 \\
\hline$q_{212}$ & 3.96 & 4.20 & 3.02 & 3.73 & 0.17 & 3.55 & 3.78 & 3.67 & 0.04 \\
\hline$q_{221}$ & 3.72 & 4.00 & 3.70 & 3.81 & 0.04 & 3.16 & 3.30 & 3.23 & 0.03 \\
\hline$q_{222}$ & 3.54 & 3.80 & 3.50 & 3.61 & 0.05 & 3.18 & 3.30 & 3.24 & 0.03 \\
\hline$q_{231}$ & 2.45 & 1.95 & 3.52 & 2.64 & 0.30 & 3.36 & 3.22 & 3.29 & 0.03 \\
\hline$q_{232}$ & 3.87 & 3.05 & 3.45 & 3.46 & 0.12 & 2.95 & 2.60 & 2.78 & 0.09 \\
\hline$q_{241}$ & 4.36 & 3.60 & 4.12 & 4.03 & 0.10 & 3.85 & 3.23 & 3.54 & 0.12 \\
\hline$q_{242}$ & 3.75 & 2.80 & 3.12 & 3.22 & 0.15 & 3.10 & 2.18 & 2.64 & 0.24 \\
\hline$q_{351}$ & 3.21 & 3.52 & 1.95 & 2.89 & 0.29 & 2.81 & 3.00 & 2.90 & 0.05 \\
\hline$q_{332}$ & 3.51 & 3.60 & 3.45 & 3.52 & 0.02 & 3.24 & 3.22 & 3.23 & 0.01 \\
\hline$q_{312}$ & 3.29 & 3.40 & 3.20 & 3.30 & 0.03 & 3.12 & 2.88 & 3.00 & 0.06 \\
\hline$q_{321}$ & 3.39 & 3.40 & 2.95 & 3.25 & 0.08 & 3.60 & 3.18 & 3.39 & 0.09 \\
\hline$q_{3 \geq 2}$ & 4.05 & 2.92 & 3.56 & 3.51 & 0.16 & 3.44 & 3.07 & 3.26 & 0.08 \\
\hline$q_{351}$ & 4.05 & 2.69 & 3.63 & 3.16 & 0.21 & 3.61 & 3.00 & 3.31 & 0.13 \\
\hline$q_{3,32}$ & 3.36 & 3.03 & 3.90 & 3.43 & 0.13 & 3.00 & 2.74 & 2.87 & 0.06 \\
\hline$q_{3,41}$ & 3.60 & 2.90 & 3.68 & 3.39 & 0.13 & 3.53 & 2.41 & 2.97 & 0.27 \\
\hline$q_{411}$ & 4.47 & 4.35 & 3.26 & 4.03 & 0.17 & 3.78 & 3.86 & 3.82 & 0.02 \\
\hline$q_{412}$ & 3.75 & 3.75 & 2.52 & 3.34 & 0.21 & 3.14 & 3.17 & 3.16 & 0.01 \\
\hline$q_{421}$ & 3.18 & 3.15 & 2.45 & 2.93 & 0.14 & 3.00 & 3.00 & 3.00 & 0.00 \\
\hline$q_{422}$ & 3.36 & 3.15 & 2.45 & 2.99 & 0.16 & 2.64 & 2.76 & 2.70 & 0.03 \\
\hline$q_{451}$ & 3.48 & 1.38 & 3.10 & 2.65 & 0.42 & 3.50 & 2.98 & 3.24 & 0.11 \\
\hline$q_{4 \dot{4} 2}$ & 3.48 & 1.74 & 2.00 & 1.87 & 0.10 & 2.89 & 2.16 & 2.53 & 0.20 \\
\hline$q_{441}$ & 3.60 & 2.55 & 3.55 & 3.23 & 0.18 & 3.16 & 2.33 & 2.74 & 0.21 \\
\hline$q_{442}$ & 3.63 & 2.62 & 3.70 & 3.32 & 0.18 & 3.10 & 2.26 & 2.68 & 0.22 \\
\hline
\end{tabular}

Note: $2 \mathrm{~V}=$ evaluation with the two valves fully open; UP=evaluation with the upstream valve fully open; DW evaluation with downstream valve fully open; $i=$ lateral number; $j=$ location within the lateral; and $k=$ order of the emitter's pair evaluated at each location.

tions. On the other hand, the degree of clogging has been estimated between 25 to $38 \%$. Thus, a proper flushing operation should be advisable to reduce these values.

\section{Simulation of the Performance of SDI Laterals}

Table 7 presents the mean values of overpressure $\bar{h}_{s}$ at the emitter A outlet [determined with Eg. (2) in the companion paper] and radius of spherical cavity $\bar{r}_{0}$ [determined with Eq. (3) in the companion paper] when inlet flow has stabilized. Values of $\bar{h}_{s}$ varied from 0.55 to $1.36 \mathrm{~m}$. The values of $\bar{r}_{0}$ are large inasmuch the soil saturated hydraulic conductivity is small. $\bar{h}_{s}$ linearly increases for the smallest discharges and tends to approach a steady value for $\bar{q} \geq 3.25 \mathrm{~L} / \mathrm{h}$. Hence, applicability of Eq. (3) in the companion paper is justified.

Surfacing was detected at different lateral locations in some tests. Big puddles were sometimes observed. These facts indicate that high overpressures developed locally in the soil. These pressures displace the soil components and create preferential paths.

Performance of laterals with Emitter A, estimated within tests conditions, are presented in Table 8. Predictions agree reasonably well with the field measurements. Likewise, the estimated mean overpressure $\bar{h}_{s}$ also agrees with the calculated values in Table 8 . As expected, the coefficient of variation of flow $\mathrm{CV}_{q}$ is a little higher (from 0.091 to 0.116 ) than the one obtained with uniform soil (from 0.077 to 0.082 ). The coefficient of variation of soil pressure $\mathrm{CV}_{h s}$ was a little higher than the discharge in uniform soils. It varied from 0.081 and 0.093 . However, its value was much higher in nonuniform soils.

For uniform soils, SDI laterals shows better uniformity than surface drip irrigation (see Table 8) as it was pointed out by Gil et al. (2008) and Rodriguez-Sinobas et al. (2009). On the contrary, if soil variability is considered, surface drip irrigation is more uniform although its difference with SDI within the tests conditions is not very large.

\section{Simulation of the Performance of SDI Units}

The tests carried out with the upstream valve fully open (UP) has been chosen to illustrate the SDI unit performance. Since flow 
Table 4. Mean Discharge from Each Pair of Evaluated Emitters and Their CV

\begin{tabular}{|c|c|c|c|c|c|c|c|c|c|c|}
\hline \multirow[b]{3}{*}{ Enitters } & \multicolumn{6}{|c|}{ Day 1} & \multicolumn{4}{|c|}{ Day 2} \\
\hline & \multicolumn{2}{|c|}{$2 \mathrm{~V}$} & \multicolumn{2}{|c|}{ UP } & \multicolumn{2}{|c|}{ DW } & \multicolumn{2}{|c|}{$2 \mathrm{~V}$} & \multicolumn{2}{|c|}{ UP } \\
\hline & $\begin{array}{c}q \\
(\mathrm{~L} / \mathrm{h})\end{array}$ & $\mathrm{CV}$ & $\begin{array}{c}q \\
(\mathrm{~L} / \mathrm{h})\end{array}$ & $\mathrm{CV}$ & $\begin{array}{c}q \\
(\mathrm{~L} / \mathrm{h})\end{array}$ & $\mathrm{CV}$ & $\begin{array}{c}q \\
(\mathrm{~L} / \mathrm{h})\end{array}$ & $\mathrm{CV}$ & $\begin{array}{c}q \\
(\mathrm{~L} / \mathrm{h})\end{array}$ & $\mathrm{CV}$ \\
\hline 11 & 3.90 & 0.011 & 4.24 & 0007 & 2.93 & 0.010 & 3.49 & 0.053 & 3.61 & 0.026 \\
\hline 12 & 3.60 & 0.147 & 3.35 & 0.331 & 3.25 & 0.330 & 3.48 & 0.098 & 3.45 & 0.184 \\
\hline 13 & 4.18 & 0.038 & 3.32 & 0.052 & 3.30 & 0.050 & 3.42 & 0.053 & 2.91 & 0.003 \\
\hline 14 & 3.63 & 0.053 & 2.87 & 0.021 & 3.70 & 0.020 & 3.53 & 0.017 & 2.81 & 0.045 \\
\hline 21 & 3.95 & 0.005 & 4.26 & 0.190 & 2.67 & 0.190 & 3.52 & 0.014 & 3.53 & 0.098 \\
\hline 22 & 3.63 & 0.035 & 3.90 & 0040 & 3.60 & 0.041 & 3.17 & 0.005 & 3.30 & 0.000 \\
\hline 23 & 3.16 & 0.318 & 2.50 & 0.012 & 3.49 & 0.011 & 3.16 & 0.091 & 2.91 & 0.149 \\
\hline 24 & 4.06 & 0.107 & 3.20 & 0.200 & 3.62 & 0.203 & 3.47 & 0.154 & 2.71 & 0.273 \\
\hline 31 & 3.36 & 0.063 & 3.56 & 0.394 & 2.70 & 0.391 & 3.02 & 0.101 & 3.11 & 0.049 \\
\hline 32 & 3.34 & 0.063 & 3.40 & 0,062 & 3.08 & 0.062 & 3.36 & 0.101 & 3.03 & 0.070 \\
\hline 33 & 4.05 & 0.022 & 2.81 & 0.011 & 3.60 & 0.015 & 3.53 & 0.034 & 3.04 & 0.017 \\
\hline 34 & 3.48 & 0.000 & 2.97 & 0.042 & 3.79 & 0.042 & 3.26 & 0.114 & 2.57 & 0.089 \\
\hline 41 & 4.11 & 0.049 & 4.05 & 0.184 & 2.89 & 0.187 & 3.46 & 0.130 & 3.52 & 0.140 \\
\hline 42 & 3.27 & 0.124 & 3.15 & 000 & 2.45 & 0.000 & 2.82 & 0.090 & 2.88 & 0.059 \\
\hline 43 & 3.48 & 0.039 & 1.56 & 0.311 & 2.55 & 0.312 & 3.20 & 0.135 & 2.57 & 0.225 \\
\hline 44 & 3.62 & 0.000 & 2.59 & 0.035 & 3.63 & 0.033 & 3.13 & 0.014 & 2.29 & 0.022 \\
\hline
\end{tabular}

Note: $2 \mathrm{~V}=$ evaluation with the two valves fully open; $\mathrm{UP}=$ evaluation with the upstream valve fully open; and DW evaluation with downstream valve fully open.

Table 5. Irtigation Uniformity Coefficients and Mean Values from the SDI Unit Evaluation

\begin{tabular}{|c|c|c|c|c|c|c|c|}
\hline & & \multicolumn{2}{|c|}{$\begin{array}{c}\bar{q} \\
(\mathrm{~L} / \mathrm{h})\end{array}$} & \multirow[b]{2}{*}{$\mathrm{CV}_{a}$} & \multirow[b]{2}{*}{$\mathrm{Cu}$} & \multicolumn{2}{|c|}{$\begin{array}{c}\text { Variation of } \bar{q} \\
(\%)\end{array}$} \\
\hline & & Water meter & Evaluation & & & Evaluation-water meter & Evaluation \\
\hline \multirow[t]{3}{*}{ Day 1} & $2 \mathrm{~V}$ & 3.41 & 3.67 & 0.11 & 91.43 & 7.08 & 0.00 \\
\hline & UP & 2.94 & 3.23 & 0.23 & 82.00 & 8.88 & 13.65 \\
\hline & DW & 2.81 & 3.20 & 0.18 & 85.55 & 12.36 & 14.73 \\
\hline \multirow[t]{2}{*}{ Day 2} & $2 \mathrm{~V}$ & 2.90 & 3.31 & 0.09 & 92.44 & 14.27 & 0.00 \\
\hline & UP & 2.58 & 3.01 & 0.12 & 90.12 & 16.91 & 9.04 \\
\hline
\end{tabular}

Note: $2 \mathrm{~V}=$ evaluation with the two valves fully open; UP=evaluation with the upstream valve fully open; and DW evaluation with downstream valve fully open.

Table 6. Irigation Uniformity Coefficients and Mean Values from SDI Unit Evaluation

\begin{tabular}{llccc}
\hline & & $2 \mathrm{~V}$ & $\mathrm{UP}$ & $\mathrm{DW}$ \\
\hline DAY 1 & $\mathrm{CV}_{q}$ & 0.108 & 0.198 & 0.153 \\
& $\mathrm{CV}_{h}$ & 0.102 & 0.042 & 0.141 \\
& $\mathrm{CV}_{m}$ & 0.038 & 0.123 & \\
DAY 2 & $\mathrm{CV}$ & 0.080 & 0.123 & \\
& $\mathrm{CV}_{h}$ & 0.064 & 0.115 & \\
& $\mathrm{CV}_{m}$ & 0.048 & 0.043 & \\
\hline
\end{tabular}

Note: $2 \mathrm{~V}=$ evaluation with the two valves fully open; UP=evaluation with the upstrean valve fully open: DW evaluation with downstream valve fully open; $h=$ hydraulic variation; and $m=$ manufacture and wear variation.

Table 7. Estimations of $\bar{h}_{s}$ and $\bar{r}_{0}$ Corresponding to the Evaluated SDI Laterals

\begin{tabular}{lcccccc}
\hline & \multicolumn{6}{c}{ Lateral } \\
\cline { 2 - 7 } & $1 \mathrm{~A}$ & $2 \mathrm{~A}$ & $3 \mathrm{~A}$ & $4 \mathrm{~A}$ & $5 \mathrm{~A}$ & $6 \mathrm{~A}$ \\
\hline $\bar{h}_{s}(\mathrm{~m})$ & 0.55 & 0.77 & 1.36 & 1.34 & 0.95 & 1.15 \\
$\bar{r}_{0}(\mathrm{~m})$ & 0.028 & 0.022 & 0.015 & 0.015 & 0.025 & 0.021 \\
\hline
\end{tabular}

regime became steady after a few minutes of irrigation and pressures are stabilized, mean values of pressure and flow have been considered in the calculations. The comparison between field measurements of pressures and emitter discharges and predictions made with the methodology proposed in the companion paper are presented in Tables 9 and 10. The last also shows: the mean emitter discharge of the emitter's sample $\bar{q}$; the discharge $\mathrm{CV}$ calculated with in the emitter's sample $\mathrm{CV}_{q}$ sample and with the whole unit $\mathrm{CV}_{q}$ unit; the inlet flow calculated with the water-meter $Q_{T}$ and the unit mean flow $\bar{Q}$. As observed, the value of $\bar{Q}$ is $14.5 \%$ smaller than the corresponding to $\bar{q}$. Moreover, $\bar{q}$ is almost $14.5 \%$ higher than the estimated from the same emitters buried in the soil. Consequently, the soil properties might have an effect in the discharge of the compensating emitters as it was pointed out in the heading hydratic chatacterization of SDI units.

Predictions of pressure measurements (see Table 9) were worse than predictions of discharges (see Table 10) with a maximum error of $18 \%$. As observed in Table 10, estimation of $\bar{q}$ coincides with $\bar{Q}$. Likewise, the discharge variability of the emitters sample is similar (error $<1 \%$ ) than the whole unit, thus for both, $\mathrm{CV}_{q} \cong 0.12$. 
Table 8. Comparison between Simulated and Measured Variables in SDI Laterals

\begin{tabular}{|c|c|c|c|c|c|c|c|c|c|c|c|c|c|c|c|c|c|c|}
\hline & & & & & & & \multicolumn{12}{|c|}{ Simulated values } \\
\hline & \multicolumn{6}{|c|}{ Measured values } & \multicolumn{6}{|c|}{ Uniform soil } & \multicolumn{6}{|c|}{ Nonuniform soil } \\
\hline & $1 \mathrm{~A}$ & $2 \mathrm{~A}$ & $3 \mathrm{~A}$ & $4 \mathrm{~A}$ & $5 \mathrm{~A}$ & $6 \mathrm{~A}$ & $1 \mathrm{~A}$ & $2 \mathrm{~A}$ & $3 \mathrm{~A}$ & $4 \mathrm{~A}$ & $5 \mathrm{~A}$ & $6 \mathrm{~A}$ & $1 \mathrm{~A}$ & $2 \mathrm{~A}$ & $3 \mathrm{~A}$ & $4 \mathrm{~A}$ & $5 \mathrm{~A}$ & $6 \mathrm{~A}$ \\
\hline $\bar{q}(\mathrm{~L} / \mathrm{h})$ & 2.76 & 2.88 & 3.27 & 3.29 & 3.96 & 3.87 & 2.79 & 2.82 & 3.21 & 3.18 & 3.95 & 3.87 & 2.75 & 2.77 & 3.13 & 3.10 & 3.91 & 3.82 \\
\hline $\bar{h}_{0}(\mathrm{~m})$ & 8.1 & 8.5 & 11.4 & 11.2 & 16.1 & 15.7 & 8.1 & 8.5 & 11.4 & 11.2 & 16.1 & 15.7 & 8.1 & 8.5 & 11.4 & 11.2 & 16.1 & 15.7 \\
\hline $\bar{h}_{L}(\mathrm{~m})$ & 5.3 & 6.0 & 7.9 & 7.9 & 11.2 & 11.1 & 5.4 & 5.8 & 8.0 & 7.8 & 11.1 & 10.9 & 5.4 & 5.8 & 8.0 & 7.9 & 11.2 & 10.9 \\
\hline $\bar{h}_{s}(\mathrm{~m})$ & 0.55 & 0.77 & 1.36 & 1.34 & 0.95 & 1.15 & 0.55 & 0.76 & 1.40 & 1.39 & 0.94 & 1.14 & 0.50 & 0.75 & 1.46 & 1.45 & 0.95 & 1.18 \\
\hline $\mathrm{CV}_{a} \leqslant \mathrm{f}$ & - & - & - & - & - & - & 0.085 & 0.085 & 0.083 & 0.083 & 0.081 & 0.081 & 0.081 & 0.081 & 0.078 & 0.079 & 0.076 & 0.076 \\
\hline $\mathrm{CV}_{q s d i}$ & - & - & - & - & - & - & 0.082 & 0.080 & 0.077 & 0.077 & 0.078 & 0.078 & 0.116 & 0.115 & 0.106 & 0.107 & 0.091 & 0.092 \\
\hline $\mathrm{CVh}_{s}$ & - & - & - & - & - & - & 0.093 & 0.088 & 0.081 & 0.081 & 0.085 & 0.083 & 2.784 & 1.850 & 0.955 & 0.963 & 1.511 & 1.215 \\
\hline
\end{tabular}

Note: sf=surface.

\section{Conclusions}

In spite of the difficulty to evaluate SDI laterals and units from measurement of discharged flow emitters in field conditions, the simulation of their performance could be achieved with the procedure presented in this paper if experimental measurements are combined with the methodology developed in the companion paper by Rodriguez-Sinobas et al. (2009). Only, few measurements, such as pressures at certain locations and inlet flow, are required to predict the distribution of water and soil pressure. Thus, inigation uniformity and soil pressure variability can be determined. Furthermore, this methodology could also improve the management of SDI systems and thus, the scarce resources such as water and energy could also be better preserved.

For loamy soils, the inlet flow of laterals with pressure compensating or regular emitters reduces at the beginning of irrigation then it tends to stabilize reaching a steady state in both evaluated models. Thus, lateral discharge of regulated emitters is affected by soil properties contradicting the behavior observed in single emitters by other researchers.

For uniform loamy soils, the $\mathrm{CV}$ of emitter flow in surface laterals is less than in subsurface laterals. However, for nonuniform it is higher in surface laterals than in subsurface laterals. Lateral inlet pressures over $10 \mathrm{~m}$ would yield better irrigation uniformity than smaller values.

Table 9. Comparison between Sinulated and Measured Head Pressures in the SDI Unit

\begin{tabular}{lcc}
\hline & Measured & Sinulated \\
\hline$h_{0-0}(\mathrm{~m})$ & 18.61 & 18.61 \\
$h_{0-0.5}(\mathrm{~m})$ & 9.02 & 9.38 \\
$h_{0-1}(\mathrm{~m})$ & 7.29 & 8.04 \\
$h_{1-0}(\mathrm{~m})$ & 16.36 & 16.51 \\
$h_{1-0.5}(\mathrm{~m})$ & 8.84 & 8.52 \\
$h_{1-1}(\mathrm{~m})$ & 5.83 & 6.89 \\
$h f_{00-00.5}(\mathrm{~m})$ & 9.59 & 9.23 \\
$h f_{00.5-01}(\mathrm{~m})$ & 1.73 & 1.34 \\
$h f_{00-01}(\mathrm{~m})$ & 11.32 & 10.57 \\
$h f_{10-10.5}(\mathrm{~m})$ & 7.53 & 7.99 \\
$h f_{10.5-11}(\mathrm{~m})$ & 3.01 & 1.62 \\
$h f_{10-11}(\mathrm{~m})$ & 10.53 & 9.62 \\
\hline
\end{tabular}

Note: $0=$ at inlet; $0.5=$ at intermediate point; $1=$ downstream end; $00=$ at the inlet of first lateral: $00.5=a$ the intermediate point of first lateral: and $01=a t$ the downstream end of first lateral. The same for last lateral 1.

\section{Acknowledgments}

We thank the Commission of Science and Technology (CICYT) for the funding received for this research through project AGL2004-01689. Likewise, we would like to thank the "Centro Nacional de Tecnología de Regadíos (CENTER)" for its contribution and support in the development of the experimental setup.

\section{Notation}

The following symbols ate used in this paper:

$$
\begin{aligned}
\mathrm{Cu}= & \text { Christiansen coefficient for irrigation } \\
& \text { uniformity }(-) ; \\
\mathrm{CV}_{h s}= & \text { variation coefficient of soil pressure at emitter } \\
& \text { outlet }(-) ; \\
\mathrm{CV}_{m}= & \mathrm{CV} \text { of emitters' manufacture and wear }(-) ;
\end{aligned}
$$

Table 10. Comparison between Flows and Inigation Uniformity Values Obtained in the Field Evaluation of the SDI Unit and the Ones Sinulated with the Proposed Methodology

\begin{tabular}{lcc}
\hline & Measured & Simulation \\
\hline$q_{11}(\mathrm{~L} / \mathrm{h})$ & 3.61 & 3.01 \\
$q_{12}(\mathrm{~L} / \mathrm{h})$ & 3.45 & 2.67 \\
$q_{13}(\mathrm{~L} / \mathrm{h})$ & 2.91 & 2.55 \\
$q_{14}(\mathrm{~L} / \mathrm{h})$ & 2.81 & 2.19 \\
$q_{21}(\mathrm{~L} / \mathrm{h})$ & 3.53 & 2.95 \\
$q_{23}(\mathrm{~L} / \mathrm{h})$ & 3.30 & 2.49 \\
$q_{23}(\mathrm{~L} / \mathrm{h})$ & 2.91 & 2.49 \\
$q_{24}(\mathrm{~L} / \mathrm{h})$ & 2.71 & 2.11 \\
$q_{31}(\mathrm{~L} / \mathrm{h})$ & 3.11 & 3.02 \\
$q_{32}(\mathrm{~L} / \mathrm{h})$ & 3.03 & 2.37 \\
$q_{3,3}(\mathrm{~L} / \mathrm{h})$ & 3.04 & 2.50 \\
$q_{34}(\mathrm{~L} / \mathrm{h})$ & 2.57 & 2.25 \\
$q_{41}(\mathrm{~L} / \mathrm{h})$ & 3.52 & 3.17 \\
$q_{42}(\mathrm{~L} / \mathrm{h})$ & 2.88 & 2.58 \\
$q_{4,3}(\mathrm{~L} / \mathrm{h})$ & 2.57 & 2.51 \\
$q_{44}(\mathrm{~L} / \mathrm{h})$ & 2.29 & 2.39 \\
$\bar{q}$ & 3.01 & 2.58 \\
$\mathrm{CV}$ & 0.124 & 0.117 \\
$Q_{T}(\mathrm{~L} / \mathrm{h} / \mathrm{h})$ & 58.714 .22 & 58.77000 \\
$\bar{Q}(\mathrm{~L} / \mathrm{h})$ & 2.58 & 2.58 \\
$\mathrm{CV}, \mathrm{wnit}$ & - & 0.121 \\
\hline
\end{tabular}




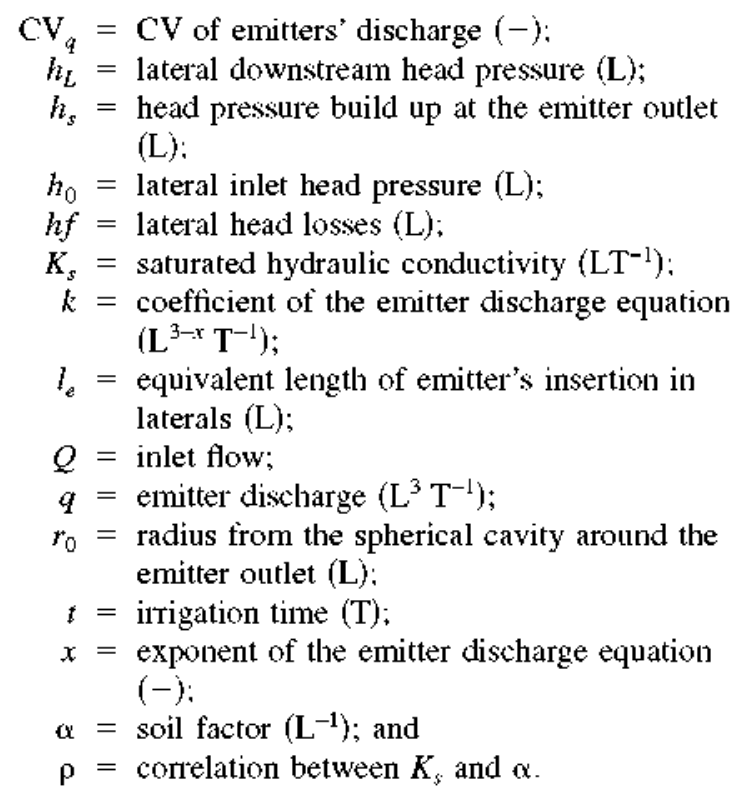

\section{Superscripts}

- $=$ mean values.

\section{Subscripts}

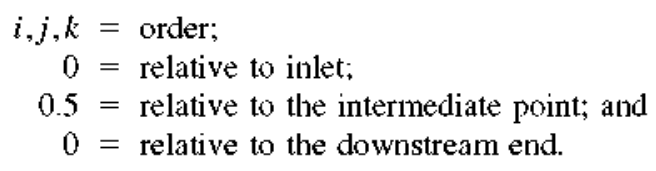

\section{References}

Ayars, J. E., et al. (1999). "Subsurface drip irtigation of row crops: A review of 15 years at the Water Management Research Laboratory." Agric. Water Manage. 42. 1-27.

Ayars. J. E. Schoneman, R. A., Dale, F., Meson, B., and Shouse, P. (2001). "Managing subsurface drip irrigation in the presence of shallow ground water." Agric. Water Manage., 47, 242-264.

Bordovsky, K. P., and Porter, D. O. (2006). "Comparison of subsurface drip irrigation uniformity designs on cotton production." ASAE Paper 06-2276, ASAE. St. Joseph, Mich.

Camp, C. R., Sadler, E. J., and Busscher, W. J. (1997). "Subsurface diip inigation lateral spacing and management for cotton in the southeastern coastal plain." Trans. ASAE, 40(4), 993-999.

Carsel, R. F., and Parrish, R. S. (1988). "Developing joint probability distributions of soil water retention characteristics." Water Resont Res., 24, 755-769.

Gil, M., Rodríguez-Sinobas, L., Juana, L., Sánchez, R., and Losada, A. (2008). "Enitter discharge variability of subsurface diip irrigation in uniform soils: Effect on water application uniformity." Irrig. $S_{c i}$. 26, $451-458$.

Gil Rodríguez. M. Rodríguez Sinobas. L. Juana Sirgado, L., Sánchez Calvo, R., and Losada Villasante, A. (2007). "Efecto del suelo en el caudal del goteo en riego subsuperficial: Deteminación de caudales máximos." Proc., XXV Jomadas Técnicas sobre Riegos (AERYD) (CD-ROM), Gobierno de Navarra, Pamplona, Spain.

Grabow, G. L.. Huffman. R. L. Evans. R. O., Jordan, D. L.. and Nuti, R. C. (2006). "Water distribution from a subsurface drip irrigation system and dripline spacing effect on cotton yield and water use efficiency in a coastal plain soil." Trans. ASAE, 49(6), 1823-1835.

Juana, L., Rodiiguez-Sinobas, L., Sanchez, R., and Losada, A. (2007). "Evaluation of diip irrigation: Selection of emitters and hydraulic characterization of trapezoidal units." Agric. Water Manage. $90(1-$ 2). $13-26$.

Lazarovitch. N.. Simunek. J. and Shani, U. (2005). "System dependent boundary conditions for water flow from a subsurface source." Soil Sci. Soc. Am. J., 69, 46-50.

Phene, C. J. Yue. R., Wu, I. P. Ayars. J. E., Schoneman. R. A., and Meso, B. (1992). "Distribution uniformity of subsurface drip irrigation systems." ASAE Paper No. 92-2569. ASAE, St. Joseph, Mich.

Rodriguez-Sinobas. L.. Juana, L.. and Losada. A. (1999). "Effects of temperature changes on emitter discharge." J. Irrig. Drain. Eng., 125(2), 64-73.

Rodriguez-Sinobas. L. M. G. Juana. L., and Sánchez, R. (2009). "Water distribution in laterals and units of subsurface drip irtigation. I: Simulation." J. Irrig. Drain. Eng., 135(6), 721-728.

Sadler, E. J., Camp. C. R., and Busscher. W. J. (1995). "Emitter flow rate changes caused by excavating subsurface microirtigation tubing." Proc., 5th Int. Microirrigation Congress, F. R. Lamm, ed., ASAE. St. Joseph, Mich., 763-768.

Safi, B., Neysahbouri, M. R.. Nazemi, A. H., Massiha, S., and Mirlatifi, S. M. (2008). "Water application uniformity of a subsurface drip irrigation system at various operating pressures and tape lengths." Turk. ish I. Agriculture and Forestry, 31, 275-285.

Shani, U. Xue, S. Gordin-Katz, R, and Warrick, A. W. (1996). "Soillimiting from subsurface emitters. I: Pressure measurements." J. Irrig. Drain. Eng., 122(5), 291-295. 